\title{
The impact of temperature on electrical properties of polymer-based nanocomposites
}

\author{
I. Karbovnyk ${ }^{1}$, H. Klym², S. Piskunov ${ }^{3}$, A. A. Popov ${ }^{3}$, D. Chalyy ${ }^{4}$, I. Zhydenko ${ }^{4}$, \\ and D. Lukashevych ${ }^{2}$ \\ ${ }^{1}$ Ivan Franko National University of Lviv, Lviv 79017, Ukraine \\ ${ }^{2}$ Lviv Polytechnic National University, Lviv 79013, Ukraine \\ ${ }^{3}$ Institute of Solid State Physics, University of Latvia, Riga LV-1063, Latvia \\ ${ }^{4}$ Lviv State University of Life Safety, Lviv 79007, Ukraine \\ E-mail: ivan.karbovnyk@lnu.edu.ua
}

Received October 6, 2020, published online October 21, 2020

\begin{abstract}
The paper discusses the results of temperature studies of polymer-based nanocomposites obtained by incorporating multi-walled carbon nanotubes in thin layers of poly(3,4-ethylenedioxythophene):poly(4-styrenesulfonate), specifically focusing on interesting features in the dependencies of electrical properties across the wide range of temperatures from ambient one down to $10 \mathrm{~K}$.
\end{abstract}

Keywords: polymer based nanocomposites, multi-walled carbon nanotubes, low-temperature hysteresis.

\section{Introduction}

Intrinsically conductive poly(3,4-ethylenedioxythiophene)poly(styrenesulfonate) (PEDOT:PSS) aqueous composites formed by doping poly(3,4-ethylenedioxythiophene) and poly(4-styrenesulfonate) are suitable for the preparation of thin films that facilitate charge transfer and are promising for a wide range of sensing application [1-4].

One of the many targeted ways of modifying polymers to obtain the desired material characteristics can be achieved by loading organic, inorganic and hybrid fillers. Such hybrid materials are of great practical interest because of their improved thermal conductivity, radiation resistance, electrical insulation of thermoplastics, and thermal performance [5-9]. Obtained hybrid nanocomposites based on organic semiconductors, ferroelectric and magnetic materials are used in light emitting devices, lighting holders, various electronic devices, motors and battery casing, temperature sensors and optimized heat exchangers [10-24].

Adding various types of carbon nanotubes in PEDOT:PSS host matrix have already been proven extremely beneficial in terms of enhancing sensing properties and improving overall performance of the material [25-27]. Most notably such advanced engineered nanomaterial is a strong candidate for flexible/rollable conductive systems seen by many as crucial components of light-weight low-cost next generation devices $[28,29]$.
Interaction of carbon nanotubes dispersed in PEDOT:PSS and basic electrical properties of such nanocomposites, including those, manufactured in the form of films on substrates were the subject of numerous theoretical and experimental studies [30-39]. Low-temperature behavior of PEDOT:PSS thin layers reinforced with carbon nanotubes however, is much less analyzed. Different reliability issues and effects of nanofiller properties on the temperature dependence of conductivity in this range remain a rather open question. In this work we report the results of the investigation of the influence of frequency and, most importantly, temperature on electrical resistivity of PEDOT:PSS micrometer thick films reinforced with multi-walled carbon nanotubes (MWCNT), prioritizing the temperature range from 10 to $300 \mathrm{~K}$.

\section{Experimental}

For the fabrication of nacomposite layers with the thickness of tens of $\mu \mathrm{m}$, intitial $1 \%$ water suspension of poly(3,4-ethylenedioxythiophene) stabilized with surface active anion substance (polystyrene sulfonic acid) was prepared. Multi-walled carbon nanotubes processed in advance as described elsewhere [40] were added to the suspension as reinforcing nanofillers. Nanotubes purity was $95 \mathrm{wt} \%$ and average outer and inner diameters were 65 and $10 \mathrm{~nm}$, respectively.

Raw materials (chemicals and nanotubes) were purchased from Sigma-Aldrich and US Research Nanomaterials, 


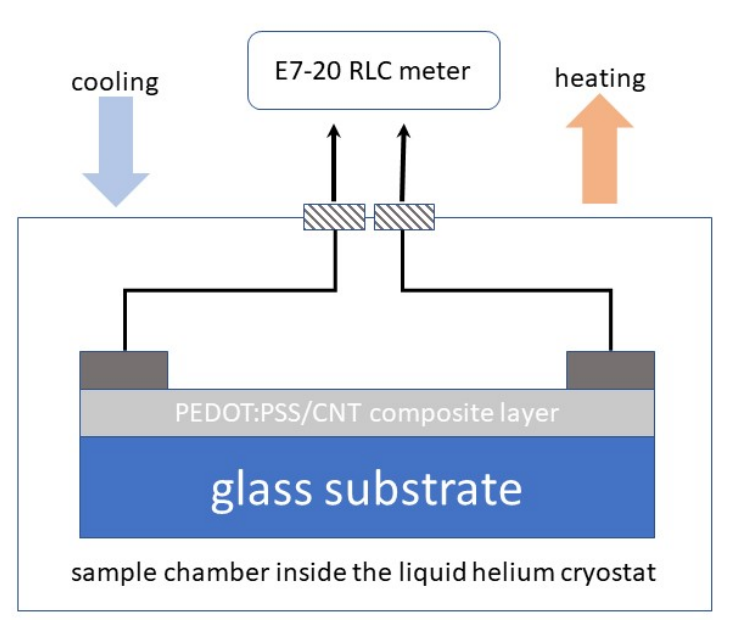

Fig. 1. Experimental configuration for low-temperature electrical tests on nanocomposite samples.

respectively. Reference sample containing no nanofiller was prepared for the purpose of comparison. The mixture was ultrasonically processed at $40 \mathrm{kHz}$ frequency $4 \mathrm{~h}$ in a row before drop-casting resulting liquid substance onto glass substrate followed by 15 min centrifugation. Samples were then dried at room temperature for two days. The concentration of nanotubes was higher than typically used to achieve percolation [41, 42], although due to lack of functionalization and advanced deagglomeration procedures, no continuous conducting networks were formed inside the obtained layers. This was partially confirmed by SEM imaging showing the presence of larger separated bundles of carbon nanotubes within the volume of the polymer. This effect is particularly pronounced in the case when multi-walled carbon nanotubes were used as nanofiller [43].

For the electrical measurements, the experimental configuration was supplied with electrodes which were deposited on the film surface with conventional silver based conductive paint. Specific resistance of the paint is $0.01 \Omega \cdot \mathrm{cm}^{3}$ and it is stable in a wide range of temperatures up until $110{ }^{\circ} \mathrm{C}$. To explore temperature dependencies of electrical properties, sample chamber was set up inside custom cryostat equipped with a DE-202A closed cycle cryocooler from Advanced Research Systems (see Fig. 1).

Cooling and heating modes of electrical measurements were realized by exploiting functions of Cryocon 32 temperature controller from Cryogenic Control Systems Inc., $a c$ electrical measurements at different frequencies were done with the automated E7-20 RLC-meter from LLC "ZAPADPRIBOR" which allows registering active and reactive resistances in the range from $10^{-5}$ to $10^{9} \Omega$. Standard $1 \mathrm{~V}$ sinewave was used as an $a c$ excitation signal.

\section{Results and discussion}

Figure 2 shows temperature dependencies of the resistances of the pristine PEDOT:PSS layer without any addition of carbon nanotubes measured in $a c$ regime at $10 \mathrm{kHz}$ and $100 \mathrm{kHz}$ frequencies.

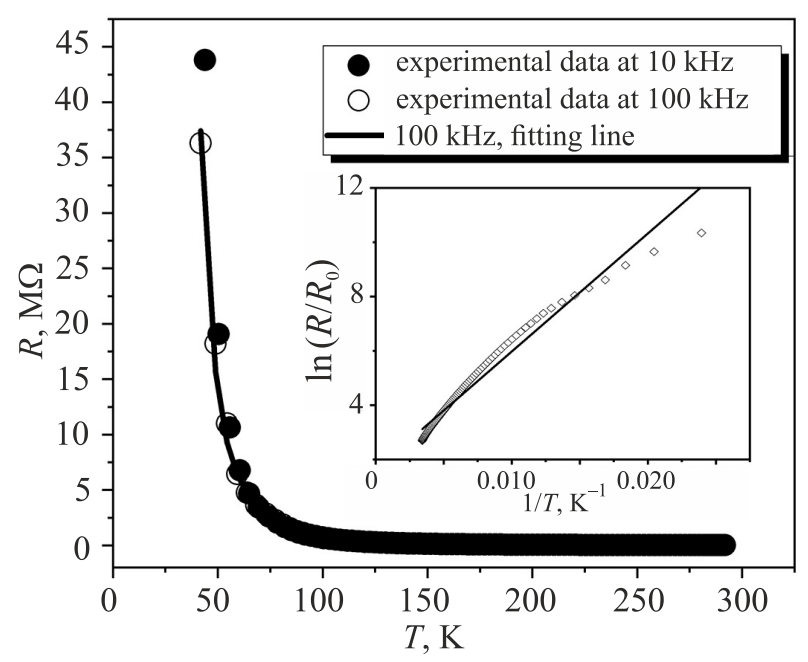

Fig. 2. Resistance vs temperature curves for thin layers of pristine PEDOT:PSS measured at $10 \mathrm{kHz}$ and $100 \mathrm{kHz}$ frequency. Inset demonstrates an attempt of Arrhenius fit of the $100 \mathrm{kHz}$ data.

At higher frequency the resistance drops slightly, though generally the dependencies in Fig. 2 are very similar. They can be described by variable hopping model [44] which is mathematically expressed as

$$
R=R_{0} \exp \left[\left(\frac{T_{0}}{T}\right)^{\frac{1}{n+1}}\right],
$$

where $T_{0}$ denotes characteristic temperature and $n$ is dimensionality parameter.

Fitting results indicate that when $n=3$, which corresponds to three-dimensional variable hopping, the model produces unrealistically large values of $T_{0}$. Instead, excellent agreement between experimental data and the model is achieved with $n=2$ (solid line in Fig. 2), being an indication of a few possible mechanisms such as nearest neighbor hooping, tunneling transport or electron-electron Coulomb interactions, the latter being specifically characteristic for low temperature range [45]. For $n=2$ the model yields $T_{0}$ value of $4483 \mathrm{~K}$, which is in line with $4210 \mathrm{~K}$ reported for $30 \mathrm{~nm}$ thin PEDOT:PSS films [46]. From inset in Fig. 2, it is obvious that conductivity does not follow simple Arrhenius thermal activation process trend, therefore most likely there is a combination of several contributions, which determines $R$ vs $T$ dependence at low temperatures.

Adding multi-walled carbon nanotubes almost does not change the resistance (or conductivity) of PEDOT:PSS layers in the range from 10 to $300 \mathrm{~K}$ as can be seen Fig. 3, right graph.

More significant effect was observed in measurement performed at $100 \mathrm{kHz}$. In this case, the dependence of resistance on temperature for PEDOT:PSS sample reinforced with multi-walled carbon nanotubes deviates substantially from the one described by Eq. 1. Notable non-linearity is observed at the lower end of the temperature range of measurement. 

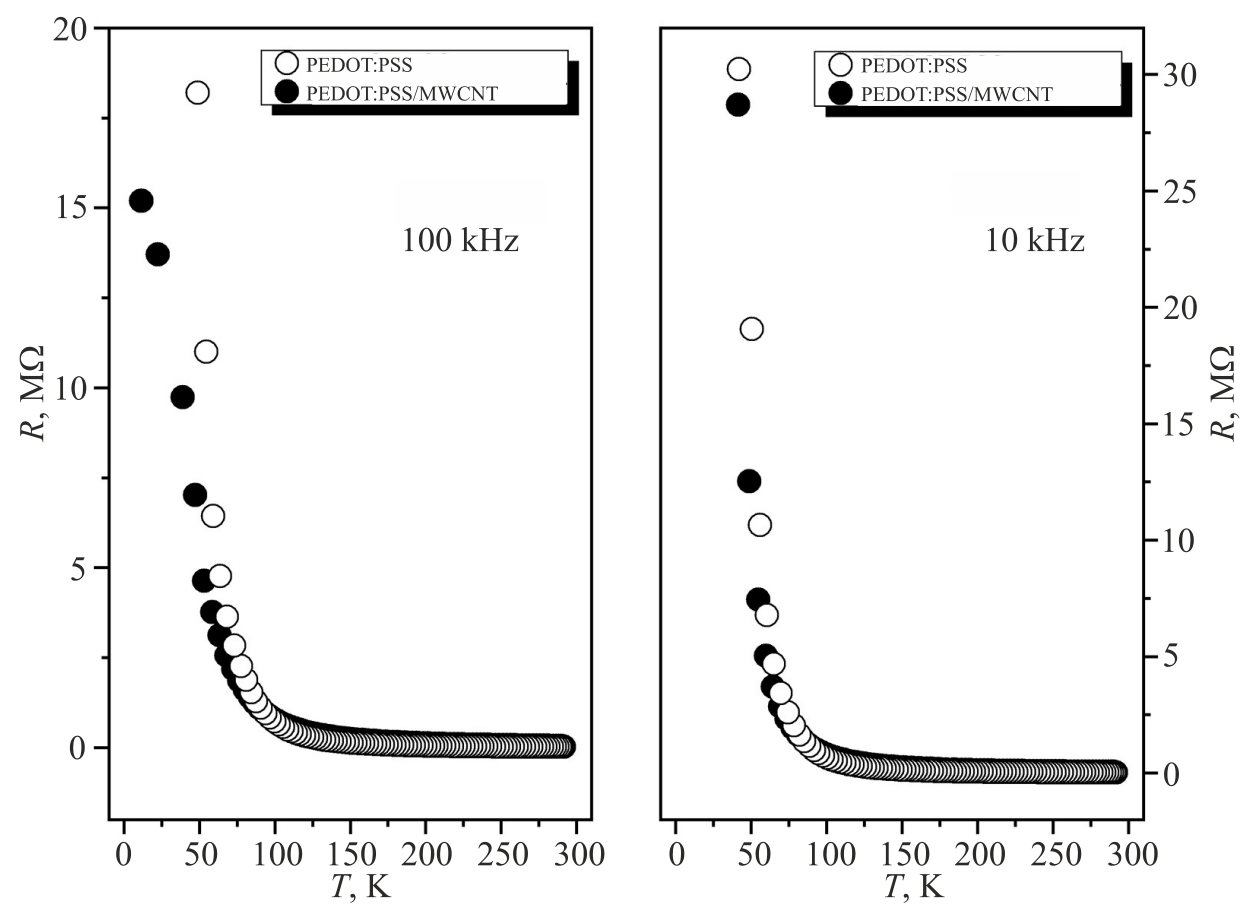

Fig. 3. Temperature variation of resistance for pristine PEDOT:PSS layers and PEDOT:PSS/MWCNT layers.

While one still has to look for an appropriate mechanism to explain such non-linear behavior, the overall decrease in resistance can be attributed to improved coherence of charge transport. Apparently, in the case of PEDOT:PSS with a composite of multiwalled carbon nanotubes, saturation is expected corresponding to a certain maximum resistance value, since the mobility edge is reached at low temperatures.

Another interesting feature observed for carbon nanotubes doped PEDOT:PSS layers in cooling-heating measurement cycles is temperature hysteresis. Measurements in cooling and heating cycles were performed at frequency $50 \mathrm{kHz}$ where non-linear behavior is not pronounced and therefore does not contribute to the effect.

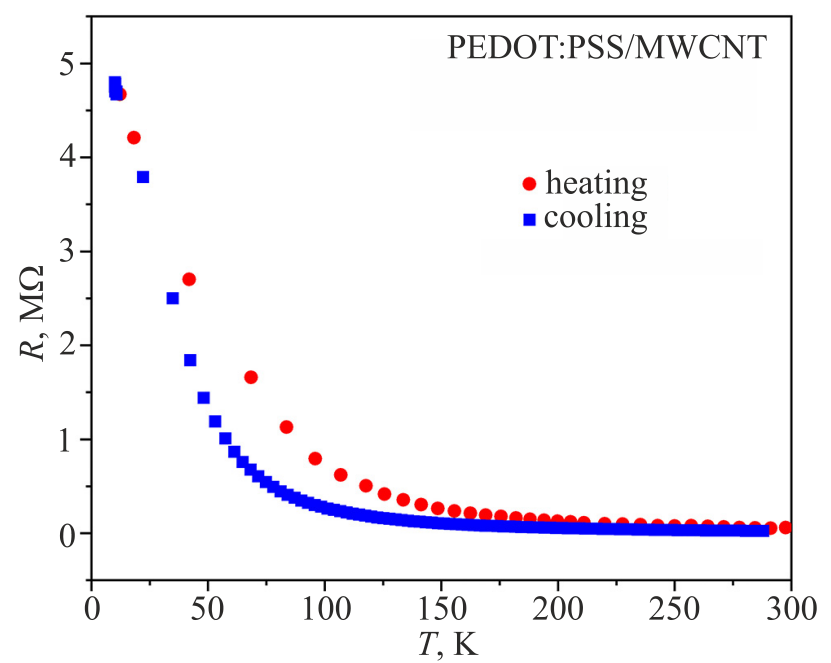

Fig. 4. Temperature dependencies of the resistance of PEDOT:PSS/MWCNT layer measured at $50 \mathrm{kHz}$ in cooling and heating regimes.
Hysteresis which is about $100 \mathrm{~K}$ wide may be facilitated by slow nature of the volume expansion/contraction processes in the structure of PEDOT:PSS modified by nanotubes with high aspect ratio.

Thus, the lateral resistance of PEDOT:PSS and PEDOT:PSS/MWCNT composite layers increases nonlinearly upon cooling from room temperature. Relatively small variation of resistance measured from room temperature down $100 \mathrm{~K}$ is followed by rapid increase of resistance as temperature decreases towards $10 \mathrm{~K}$. Layers, containing multi-walled nanotubes usually show lower resistance compared to the original PEDOT:PSS specimens, with the effect being more pronounced at higher frequencies. Generally, the obtained experimental results and their modeling indicate that several conduction mechanisms at low temperatures can be realized simultaneously.

\section{Conclusions}

Two types of layers of conductive polymer PEDOT:PSS and polymer PEDOT:PSS with the addition of multilayer carbon nanotubes were prepared, with a thickness in the range of 30-50 $\mu \mathrm{m}$. The electrical resistance of such layers was investigated depending on the temperature in the range of $10-300 \mathrm{~K}$.

The observed temperature behavior of PEDOT:PSS resistance is consistent line with one-dimensional variable hopping model, which speaks speaking in favor of possible partial contribution of tunneling conduction, as well as thermal activation mechanism and, possibly, Coulomb electron-electron interaction.

The effect of adding nanotubes to the polymer matrix results also leads to the hysteresis of resistance measured 
in heating-cooling cycles, which is probably likely to be stimulated by the difference in thermal expansion coefficients of the matrix and the filler and by slow processes determined by these coefficients.

\section{Acknowledgements}

This work was supported by National Research Foundation of Ukraine, project 2020.02/0217. IK would also like to thank VIAA, State Education Development Agency for Latvian state fellowship. HK would like to thank Ministry of Education and Science of Ukraine, project for young researchers No. 0119U100435. In addition, SP and AAP are thankful for financial support from Latvian Council of Science via grant lzp-2018/2-0083. HK and AAP are grateful for the support from the COST Action CA17126.

1. I. B. Olenych, O. I. Aksimentyeva, L. S. Monastyrskii, Y. Y. Horbenko, and L. I. Yarytska, Nanoscale Res. Lett. 10, 187 (2015).

2. S. P. Rwei, Y. H. Lee, J. W. Shiu, R. Sasikumar, and U. T. Shyr, Polymers 11, 134 (2019).

3. L. Peng and Z. Liu, J. Mater. Chem. C 7(20), 6120 (2019).

4. J. Luo, D. Billep, T. Waechtler, T. Otto, M. Toader, O. Gordan, E. Sheremet, J. Martin, M. Hietschold, D. R. T. Zahn, and T. Gessner, J. Mater. Chem. A 1(26), 7576 (2013).

5. X. Tian, M. E. Itkis, and R. C. Haddon, Sci. Rep. 5, 13108 (2015).

6. A. Lobko, V. Kazhuro, N. Valynets, S. Bellucci, A. Celzard, J. Zicans, and P. Kuzhir, Nucl. Instrum. Methods Phys. Res. B 435, 242 (2018).

7. M. Derradji, A. Zegaoui, Y. Xu, A. Wang, A. Dayo, J. Wang, W. Liu, Y. Liu, and K. Khiari, Nucl. Instrum. Methods Phys. Res. B 421, 13 (2018).

8. K. Ivaniuk, V. Cherpak, P. Stakhira, G. Baryshnikov, B. Minaev, Z. Hotra, P. Turyk, Ya. Zhydachevskii, D. Volyniuk, O. Aksimentyeva, B. Penyukh, A. Lazauskas, S. Tamulevicius, J. V. Grazulevicius, and H. Ågren, Dyes Pigm. 145, 399 (2017).

9. V. P. Savchyn, A. I. Popov, O. I. Aksimentyeva, H. Klym, Y. Y. Horbenko, V. Serga, A. Moskina, and I. Karbovnyk, Fiz. Nizk. Temp. 42, 760 (2016) [Low Temp. Phys. 42, 597 (2016)].

10. H. V. Rusakova, L. S. Fomenko, S. V. Lubenets, A. V. Dolbin, N. A. Vinnikov, R. M. Basnukaeva, M. V. Khlistyuck, and A. V. Blyznyuk, Fiz. Nizk. Temp. 46, 336 (2020) [Low Temp. Phys. 46, 276 (2020)].

11. S. Bellucci, C. Balasubramanian, A. Grilli, F. Micciulla, A. Raco, A. Popov, V. Baranov, V. Biryukov, Y. Chesnokov, and V. Maisheev, Nucl. Instrum. Methods Phys. Res. B 252, 3 (2006).

12. N. I. Ostapenko, O. A. Kerita, Yu. V. Ostapenko, and M. V. Chursanova, Fiz. Nizk. Temp. 45, 874 (2019), [Low Temp. Phys. 45, 748 (2019)].

13. J. Bitenieks, R. Merijs Meri, J. Zicans, and K. Buks, Int. J. Polym. Sci. 2020, 5715463 (2020).
14. M. Turemis, D. Zappi, M. T. Giardi, G. Basile, A. Ramanaviciene, A. Kapralovs, A. Ramanavicius, and R. Viter, Talanta 211, 120658 (2020).

15. O. I. Aksimentyeva, V. P. Savchyn, V. P. Dyakonov, S. Piechota, Y. Y. Horbenko, I. Y. Opainych, P. Y. Demchenko, A. Popov, and H. Szymczak, Mol. Cryst. Liq. Cryst. 590, 35 (2014).

16. O. Starkova, S. T. Buschhorn, L. A. S. de Almeida Prado, P. Pötschke, M. Edelmann, and K. Schulte, Macromol. Mater. Eng. 299, 41 (2014).

17. O. Starkova, S. Chandrasekaran, L. A. S. A. Prado, F. Tölle, R. Mülhaupt, and K. Schulte, Polym. Degrad. Stabil. 98, 519 (2013).

18. T. Glaskova, K. Aniskevich, and A. Borisova, J. Appl. Polym. Sci. 129, 3314 (2013).

19. I. V. Korolkov, K. Ludzik, A. L. Kozlovskiy, M. S. Fadeev, A. E. Shumskaya, Ye. G. Gorin, M. Jazdzewska, M. Anisovich, V. S. Rusakov, and M. V. Zdorovets, Colloids Surf. A: Physicochem. Eng. Asp. 601, 125035 (2020).

20. A. A. Mashentseva, A. L. Kozlovskiy, and M. V. Zdorovets, Mater. Res. Express 5, 065041 (2018).

21. R. O. Medupin, O. K. Abubakre, A. S. Abdulkareem, R. A. Muriana, and A. S. Abdulrahman, Sci. Rep. 9, 20146 (2019).

22. F. Ji, C. Liu, Y. Hu, S. Xu, Y. He, J. Zhou, and Y. Zhang, Materials 13, 3813 (2020).

23. Y.-R. Son and S.-J. Park, Sci. Rep. 8, 17601 (2018).

24. E. R. Lee, S. E. Shin, N. Takata, M. Kobashi, and M. Kato, Materials 13, 3927 (2020).

25. I. Karbovnyk, I. Olenych, O. Aksimentyeva, H. Klym, O. Dzendzelyuk, Yu. Olenych, and O. Hrushetska, Nanoscale Res. Lett. 11, 84 (2016).

26. T. Vuorinen, J. Niittynen, T. Kankkunen, T. M. Kraft, and M. Mäntysalo, Sci. Rep. 6, 35289 (2016).

27. K. Dunst, K. J. Karczewski, and P. Jasiński, Sensors Actuat. B-Chem. 247, 108 (2017).

28. S. Khan and L. Lorenzelli, Smart Mater. Struct. 26, 083001 (2017).

29. M. Zhang and J. T. Yeow, Carbon 156, 339 (2020).

30. A. M. Nardes, R. A. Janssen, and M. Kemerink, Adv. Funct. Mater. 18, 865 (2008).

31. A. Dkhissi, D. Beljonne, and R. Lazzaroni, Synth. Met. 159, 546 (2009).

32. G. S. Lonakar, M. S. Mahajan, S. S. Ghosh, and J. V. Sali, Org. Electron. 13, 2575 (2012).

33. M. Feinaeugle, P. Horak, C. L. Sones, T. Lippert, and R. W. Eason, Appl. Phys. A 116, 1939 (2014).

34. Y. Lin, Y. Zhao, Q. Xin, C. Jiang, and A. Song, Opt. Mater. 108, 110435 (2020).

35. Q. Zhu, E. Yildirim, X. Wang, A. K. K. Kyaw, T. Tang, T. X. Y. D. Soo, Z. M. Wong, G. Wu, Sh-W. Yang, and J. Xu, Mol. Syst. Des. Eng. 5, 976 (2020).

36. E. Yildirim, G. Wu, X. Yong, T. L. Tan, Q. Zhu, J. Xu, J. Ouyang, J. S. Wang, and S. W. Yang, J. Mater. Chem. C 6, 5122 (2018). 
37. A. Stelmashchuk, I. Karbovnyk, and H. Klym, IEEE 13th International Conference on Modern Problems of Radio Engineering, Telecommunications and Computer Science (TCSET) (2016), p. 415.

38. A. Stelmashchuk, I. Karbovnyk, H. Klym, O. Berezko, Yu. Kostiv, and R. Lys, East.-Eur. J. Enterp. Technol. 5, 4 (2017).

39. A. Stelmashchuk, I. Karbovnyk, H. Klym, D. Lukashevych, and D. Chalyy, IEEE 37th International Conference on Electronics and Nanotechnology (ELNANO) (2017), p. 209.

40. I. Karbovnyk, H. Klym, D. Lukashevych, D. Chalyy, and I. Zhydenko, IEEE 40th International Conference on Electronics and Nanotechnology (ELNANO) (2020), p. 351.

41. Yu. Olenych, I. Karbovnyk, and H. Klym, IEEE XIV-th International Conference on Perspective Technologies and Methods in MEMS Design (MEMSTECH) (2018), p. 48.

42. A. Stelmashchuk, I. Karbovnyk, D. Chalyy, D. Lukashevych, and H. Klym, IEEE First Ukraine Conference on Electrical and Computer Engineering (UKRCON) (2017), p. 740.

43. I. Karbovnyk, Yu. Olenych, H. Klym, I. Bolesta, D. Lukashevych, D. Chalyy, and I. Zhydenko, IEEE 39th International Conference on Electronics and Nanotechnology (ELNANO) (2019), p. 344.

44. A. M. Nardes, On the conductivity of PEDOT:PSS thin films, Technische Universiteit Eindhoven, Eindhoven (2007), p. 132.
45. M. N. Gueye, A. Carella, J. Faure-Vincent, R. Demadrille, and J. P. Simonato, Prog. Mater. Sci. 108, 100616 (2020).

46. I. W. Kwon, H. J. Son, W. Y. Kim, Y. S. Lee, and H. C. Lee, Synth. Met. 159, 1174 (2009).

\section{Вплив температури на електричні властивості полімерних нанокомпозитів}

\section{Karbovnyk, H. Klym, S. Piskunov, A. A. Popov, D. Chalyy, I. Zhydenko, D. Lukashevych}

Обговорено результати температурних досліджень нанокомпозитів на основі полімерів, які одержані включенням багатостінних вуглецевих нанотрубок у тонкі шари poly(3,4-ethylenedioxythophene):poly(4-styrenesulfonate). Значну увагу приділено особливостям температурної залежності електричних властивостей у широкому інтервалі температур: від температури навколишнього середовища до 10 К.

Ключові слова: полімерні нанокомпозити, багатостінні вуглецеві нанотрубки, низькотемпературний гістерезис.

Institute of Solid State Physics, University of Latvia as the Center of Excellence has received funding from the European Union's Horizon 2020 Framework Programme H2020-WIDESPREAD-01-2016-2017-TeamingPhase2 under grant agreement No. 739508, project CAMART ${ }^{2}$ 